\title{
A Method to Simulate the Skew Normal Distribution
}

\author{
Dariush Ghorbanzadeh, Luan Jaupi, Philippe Durand \\ CANAM-Département IMATH, Paris, France \\ Email: dariush.ghorbanzadeh@cnam.fr, jaupi@cnam.fr, philippe.durand@cnam.fr
}

Received 2 May 2014; revised 10 June 2014; accepted 17 June 2014

Copyright (C) 2014 by authors and Scientific Research Publishing Inc.

This work is licensed under the Creative Commons Attribution International License (CC BY). http://creativecommons.org/licenses/by/4.0/

c) (†) Dpen Access

\section{Abstract \\ A new method is developed to simulate the skew normal distribution. The result is interesting from a practical as well as a theoretical viewpoint. The new method is simple to program and is more efficient than the standard method of simulation by acceptance-rejection method.}

\section{Keywords}

\section{Normal Distribution, Skew Normal Distribution}

\section{Introduction}

In this paper, we denote by $S N(\theta)$ the skew normal distribution of parameter $\theta$ and density:

$$
f(x)=2 \varphi(x) \Phi(\theta x)
$$

where $\varphi$ and $\Phi$ denote the standard normal $\mathcal{N}(0,1)$ probability density function and cumulative distribution function, respectively.

The skew normal distribution, due to its mathematical tractability and inclusion of the standard normal distribution, has attracted a lot of attention in the literature. Azzalini [1], Azzalini [2], Chiogna [3], Genton \& Liu [4] and Henze [5] discussed basic mathematical and probabilistic properties of the skew normal family. The multivariate skew normal distribution is studied by Azzalini \& Capitanio [6] and Azzalini \& Dalla Valle [7]. For additional references and a review on related literature, see Azzalini \& Capitanio [8] and Pewsey [9] for a collection of papers on the subject. Henze [5], in his paper showed that if $U_{1}$ and $U_{2}$ are identically and independently distributed $\mathcal{N}(0,1)$ random variables, then $\frac{\theta\left|U_{1}\right|+U_{2}}{\sqrt{1+\theta^{2}}}$ has the skew normal distribution.

For the simulation of the skew normal distribution, we propose a combinations of maximum and minimum of 
the independent and identically distributed $\mathcal{N}(0,1)$ random variables.

\section{Method}

Let $U_{1}$ and $U_{2}$ two independent and identically distributed $\mathcal{N}(0,1)$ random variables and $U=\max \left(U_{1}, U_{2}\right)$ and $V=\min \left(U_{1}, U_{2}\right)$. For simulation of the random variable $X \sim S N(\theta)$, we take the combination of $U$ and $V$. First note that:

- if $\theta=0$, the density (1) becomes: $f(x)=\varphi(x)$, simply simulate $X \sim \mathcal{N}(0,1)$.

- if $\theta=-1$, the density (1) becomes: $f(x)=2 \varphi(x)(1-\Phi(x))$, we take $X=V$.

- if $\theta=1$, the density (1) becomes: $f(x)=2 \varphi(x) \Phi(x)$, we take $X=U$.

For $\theta \notin\{-1,0,1\}$, note :

$$
\lambda_{1}=\frac{1+\theta}{\sqrt{2\left(1+\theta^{2}\right)}}, \quad \lambda_{2}=\frac{1-\theta}{\sqrt{2\left(1+\theta^{2}\right)}}
$$

We note that: $\lambda_{1}^{2}+\lambda_{2}^{2}=1$. For simulation of the random variable $X \sim S N(\theta)$, we take the combination of $U$ and $V$ in the form:

$$
X=\lambda_{1} U+\lambda_{2} V
$$

Proposition The random variable $X$ defined in the Equation (3) has the skew normal distribution $S N(\theta)$.

Proof. The pair $(U, V)$ has density: $f_{U, V}(u, v)=2 \varphi(u) \varphi(v) l_{\{v \leq u\}}(u, v)$, where 11 is the indicator function.

Consider the transformation: $x=\lambda_{1} u+\lambda_{2} v, y=\lambda_{1} u$. The inverse transform is defined by: $u=\frac{y}{\lambda_{1}}, v=\frac{x-y}{\lambda_{2}}$ and the corresponding Jacobian is: $J=\frac{1}{\lambda_{1} \lambda_{2}} \cdot X$ density is defined by:

$$
f(x)=\frac{2}{\left|\lambda_{1} \lambda_{2}\right|} \int_{\Delta} \varphi\left(\frac{y}{\lambda_{1}}\right) \varphi\left(\frac{x-y}{\lambda_{2}}\right) \mathrm{d} y
$$

where $\Delta=\left\{\frac{x-y}{\lambda_{2}} \leq \frac{y}{\lambda_{1}}\right\}$. Taking into account $\lambda_{1}^{2}+\lambda_{2}^{2}=1$, we can write:

$$
\varphi\left(\frac{y}{\lambda_{1}}\right) \varphi\left(\frac{x-y}{\lambda_{2}}\right)=\varphi(x) \varphi\left(\frac{y-\lambda_{1}^{2} x}{\left|\lambda_{1} \lambda_{2}\right|}\right)
$$

Equation (4) becomes,

$$
f(x)=\frac{2 \varphi(x)}{\left|\lambda_{1} \lambda_{2}\right|} \int_{\Delta} \varphi\left(\frac{y-\lambda_{1}^{2} x}{\left|\lambda_{1} \lambda_{2}\right|}\right) d y
$$

For the domain $\Delta$, we have the following three cases:

Case 1: $\theta \in(-1,0) \cup(0,1)$, we have: $\left|\lambda_{1} \lambda_{2}\right|=\frac{1-\theta^{2}}{2\left(1+\theta^{2}\right)}$ and $\Delta=\left\{y \geq \frac{\lambda_{1} x}{\lambda_{1}+\lambda_{2}}\right\}$

Case 2: $\theta<-1$, we have: $\left|\lambda_{1} \lambda_{2}\right|=\frac{\theta^{2}-1}{2\left(1+\theta^{2}\right)}$ and $\Delta=\left\{y \geq \frac{\lambda_{1} x}{\lambda_{1}+\lambda_{2}}\right\}$

Case 3: $\theta>1$, we have: $\left|\lambda_{1} \lambda_{2}\right|=\frac{\theta^{2}-1}{2\left(1+\theta^{2}\right)}$ and $\Delta=\left\{y \leq \frac{\lambda_{1} x}{\lambda_{1}+\lambda_{2}}\right\}$

Using Equation (6) and the three cases above, we get the result.

\section{Simulation Results}

We simulated a sample of size 500,000 for the values $\theta=-7$ and $\theta=13$, The following Figure 1, Figure 2 
and Table 1, Table 2 show the results obtained by our method and the method Henze [5].

The results of Table 1 and Table 2 show that our method provides results close to the theoretical values and secondly, we obtain results similar to those obtained by Henze [5] results.

\section{Conclusion}

In this article we propose a very simple method to simulate skew normal family distribution. The obtained

Table 1. Simulation results for a sample size of 500,000 and $\theta=-7$.

\begin{tabular}{cccc}
\hline & \multicolumn{3}{c}{$\theta=-7$} \\
& Theoretical value & Simulated value $^{\mathrm{a}}$ & Simulated value $^{\mathrm{b}}$ \\
\hline Mean & -0.789865 & -0.789651 & -0.790496 \\
Variance & 0.376113 & 0.375669 & 0.376671 \\
Skewness & -0.916950 & -0.915649 & -0.924019 \\
Kurtosis & 0.779197 & 0.768095 & 0.796781 \\
\hline
\end{tabular}

aby our method; by the method of Henze [5].

Table 2. Simulation results for a sample size of 500,000 and $\theta=13$.

\begin{tabular}{cccc}
\hline & $\theta=13$ & & \\
& & & \\
& Theoretical value & Simulated value $^{\mathrm{a}}$ & Simulated value $^{\mathrm{b}}$ \\
\hline Mean & 0.795534 & 0.795174 & 0.795930 \\
Variance & 0.367125 & 0.366461 & 0.367464 \\
Skewness & 0.971447 & 0.969756 & 0.970813 \\
Kurtosis & 0.841547 & 0.836937 & 0.831219 \\
\hline
\end{tabular}

aby our method; bby the method of Henze [5].

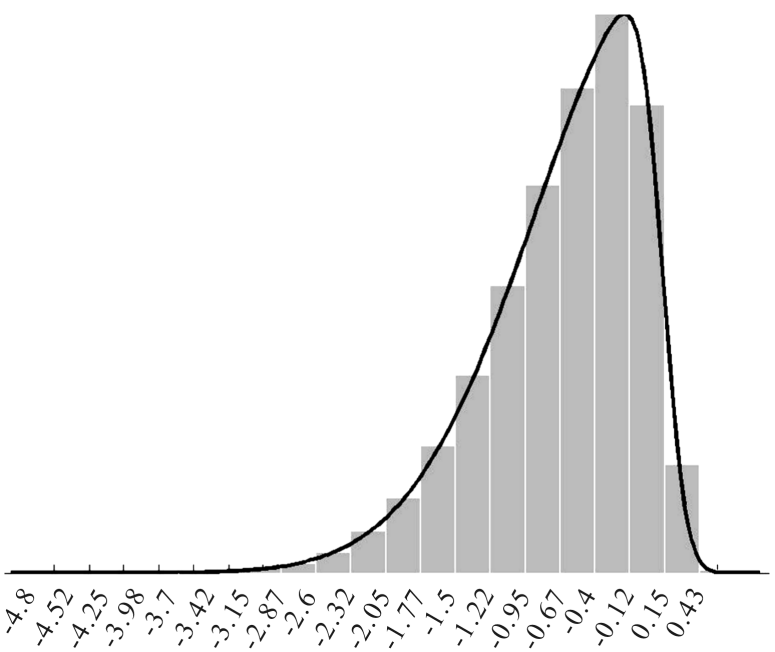

(a)

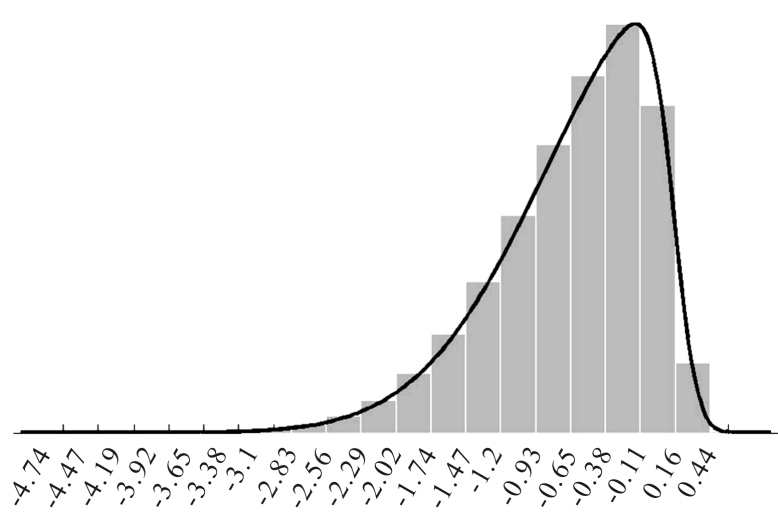

(b)

Figure 1. Histogram of simulations for a sample size of 500,000 and $\theta=-7$. (a) histogram of simulations using our method; (b) histogram of simulations using the method of Henze [5]. 


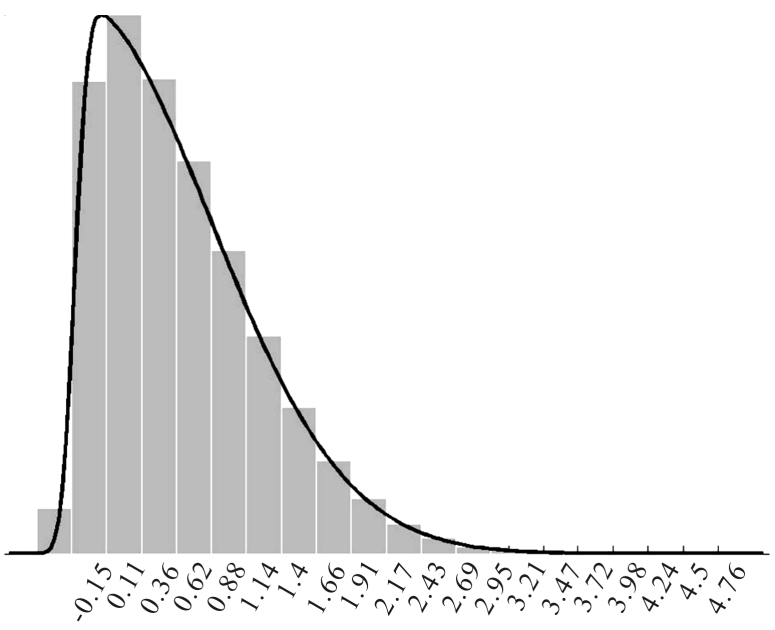

(a)

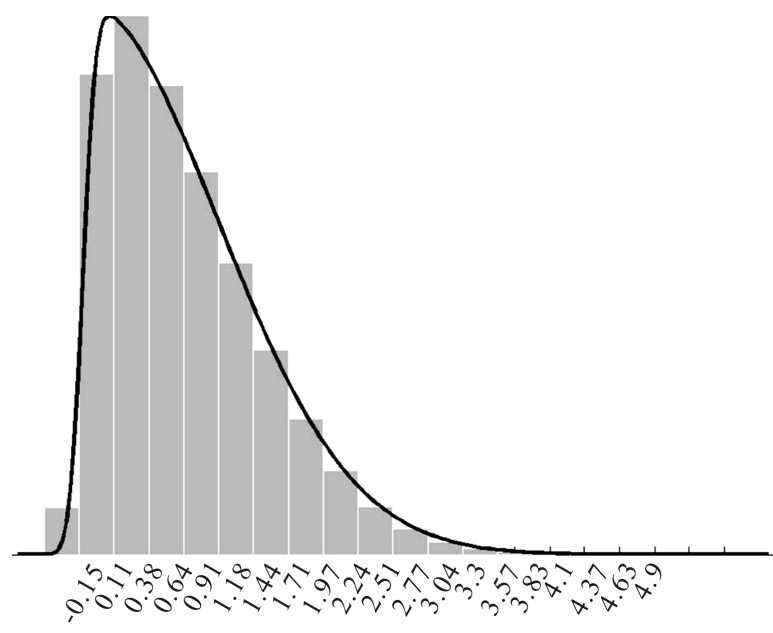

(b)

Figure 2. Histogram of simulations for a sample size of 500,000 and $\theta=13$. (a) histogram of simulations using our method; (b) histogram of simulations using the method of Henze [5].

results are very close to theoretical values and the method is more efficient than the standard one. The method is simple to program and exploit for practical applications.

\section{References}

[1] Azzalini, A. (1985) A Class of Distributions Which Includes the Normal Ones. Scandinavian Journal of Statistics, 12, 171-178.

[2] Azzalini, A. (1986) Further Results on the Class of Distributions Which Includes the Normal Ones. Statistica, 46, 199208.

[3] Chiogna, M. (1998) Some Results on the Scalar Skew-Normal Distribution. Journal of the Italian Statistical Society, 1, 1-13. http://dx.doi.org/10.1007/BF03178918

[4] Genton, M.G., He, L. and Liu, X. (2001) Moments of Skew Normal Random Vectors and Their Quadratic Forms. Statistics \& Probability Letters, 51, 319-325. http://dx.doi.org/10.1016/S0167-7152(00)00164-4

[5] Henze, N. (1986) A Probabilistic Representation of the Skew-Normal Distribution. Scandinavian Journal of Statistics, 13, 271-275.

[6] Azzalini, A. and Capitanio, A. (1999) Statistical Applications of the Multivariate Skew-Normal Distributions. Journal of the Royal Statistical Society, Series B, 61, 579-602. http://dx.doi.org/10.1111/1467-9868.00194

[7] Azzalini, A. and Dalla Valle, A. (1996) The Multivariate Skew-Normal Distribution. Biometrika, 83, 715-726. http://dx.doi.org/10.1093/biomet/83.4.715

[8] Azzalini, A. and Capitanio, A. (2003) Distributions Generated by Perturbation of Symmetry with Emphasis on a Multivariate Skew t Distribution. Journal of the Royal Statistical Society, Series B, 65, 367-389. http://dx.doi.org/10.1111/1467-9868.00391

[9] Pewsey, A. (2000) Problems of Inference for Azzalini’s Skew-Normal Distribution. Journal of Applied Statistics, 27, 859-870. http://dx.doi.org/10.1080/02664760050120542 
Scientific Research Publishing (SCIRP) is one of the largest Open Access journal publishers. It is currently publishing more than 200 open access, online, peer-reviewed journals covering a wide range of academic disciplines. SCIRP serves the worldwide academic communities and contributes to the progress and application of science with its publication.

Other selected journals from SCIRP are listed as below. Submit your manuscript to us via either submit@scirp.org or Online Submission Portal.
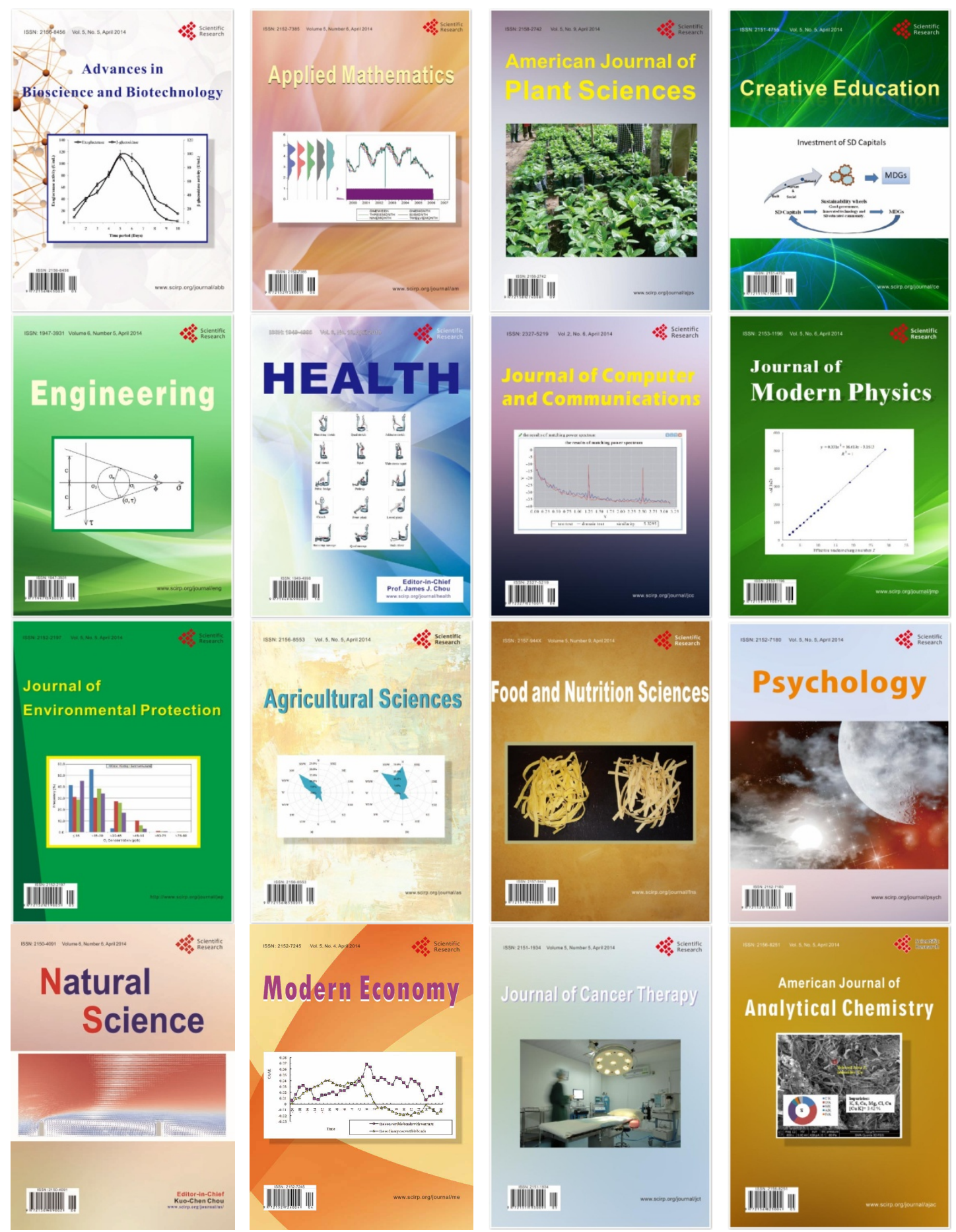